Maria Paula Boechat Borges de Macedo

\title{
Análise de Potenciais Bases de Exportação de Cerveja Heineken na América do Sul
}

Dissertação apresentada como requisito parcial para obtenção do grau de Mestre (opção profissional) pelo Programa de Pós-Graduação em Engenharia de Produção do Departamento de Engenharia Industrial da PUC-Rio.

Orientador: Prof. Dr. Madiagne Diallo 


$$
\text { Pontifícia } \text { Universidade }_{\text {Do Rio de Janeiro }} \text { C }_{\text {atólica }}
$$

\section{Maria Paula Boechat Borges de Macedo}

\section{Análise de Potenciais Bases de Exportação de Cerveja Heineken na América do Sul}

Dissertação apresentada como requisito parcial para obtenção do grau de Mestre (opção profissional) pelo Programa de Pós-Graduação em Engenharia de Produção do Departamento de Engenharia Industrial da PUC-Rio. Aprovada pela Comissão Examinadora abaixo assinada.

Prof. Dr. Madiagne Diallo Orientador

Departamento de Engenharia Industrial - PUC-Rio

Prof. Dr. José Eugenio Leal

Departamento de Engenharia Industrial - PUC-Rio

Prof. Dr. Nelio Pizzolato Departamento de Engenharia Industrial - PUC-Rio

Prof. Dr. José Eugenio Leal Coordenador Setorial do Centro Técnico Científico - PUC-Rio 
Todos os direitos reservados. É proibida a reprodução total ou parcial do trabalho sem autorização da universidade, do autor e do orientador.

\section{Maria Paula Boechat Borges de Macedo}

Graduou-se em Administração de Empresas pela PUC Rio em 2002. É Mestre em Administração e Direção de Empresas pela "Escuela Europea de Negocios" (EEN, Espanha) e Mestre em Logística pela PUC-Rio. Trabalhou por cerca de quatro anos com logística internacional em empresas tais como: General Electric - GE, Heineken Latin America e Rio Polímeros Petroquímica. Atualmente, é servidora pública no cargo de Especialista em Regulação na Agência Nacional de Aviação Civil - ANAC.

Ficha Catalográfica

Macedo, Maria Paula Boechat Borges de

Análise de potenciais bases de exportação de cerveja Heineken na América do Sul / Maria Paula Boechat Borges de Macedo ; orientador: Madiagne Diallo. - 2008.

50 f. : il. ; $30 \mathrm{~cm}$

Dissertação (Mestrado em Engenharia Industrial)Pontifícia Universidade Católica do Rio de Janeiro, Rio de Janeiro, 2008.

Inclui bibliografia

1. Engenharia Industrial - Teses. 2. Fluxos em rede. 3. Distribuição. 4. Exportação. I. Diallo, Madiagne. II. Pontifícia Universidade Católica do Rio de Janeiro. Departamento de Engenharia Industrial. III. Título. 


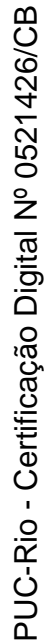

Para minha família, pelo apoio e inspiração. 


\section{Agradecimentos}

Agradeço aos meus pais, Walter e Paula, por sempre acreditarem e apostarem em mim. Por terem me ensinado a importância do estudo e do contínuo aprendizado e por terem me ajudado a realizar mais este sonho.

Ao meu marido Marcelo, companheiro e cúmplice, cuja perseverança e força de vontade me inspiram a vencer desafios e me fazem crescer. Obrigada por insistir que eu seguisse adiante, mesmo quando me deparei com obstáculos que pareciam intransponíveis.

Agradeço também ao meu orientador, Prof. Madiagne Diallo, por ter depositado em mim sua confiança e acreditado em minha capacidade de desenvolver um bom trabalho. Obrigada pela paciência e interesse demonstrado na qualidade do resultado final deste trabalho. 


\section{Resumo}

Macedo, Maria Paula Boechat Borges de; Diallo, Madiagne. Análise de Potenciais Bases de Exportação de Cerveja Heineken na América do Sul. Rio de Janeiro, 2008. 50p. Dissertação de Mestrado (opção profissional) - Departamento de Engenharia Industrial, Pontifícia Universidade Católica do Rio de Janeiro.

A Cerveja Heineken está presente em onze países da América Latina. Alguns têm sua demanda suprida por plantas industriais localizadas no próprio território, outros pela importação a partir de plantas localizadas em outros países da região e ainda há aqueles que dependem do fornecimento de cerveja da matriz da empresa localizada na Holanda. Considerando os mercados latino-americanos que são supridos regularmente por plantas industriais localizadas no exterior, apresentam-se três fornecedores (sources) distintos: Holanda, Argentina e Chile. Motivada pelo grande volume de cerveja importado da Heineken Holanda, pelos custos gerados por estas importações e ainda pelos problemas ocasionados pela dificuldade de algumas plantas cervejeiras locais em atender a demanda externa entende-se por "locais" aquelas localizadas na região da América Latina -, esta dissertação se desenvolve. Assim, o intuito desse estudo é analisar a dinâmica da rede de distribuição de Cerveja Heineken para os países da América Latina, com vistas a identificar potenciais novas bases e propor uma melhor organização do fluxo de exportação. O objetivo é otimizar esse fluxo, reduzindo custos através da regionalização das chamadas sources, que nada mais são do que as plantas industriais cervejeiras que exportam e suprem os diversos países latinoamericanos. Para atender a este propósito, serão testadas potenciais sources e avaliados, por meio de ferramentas logísticas, os cenários que poderão suprir de forma mais eficaz os mercados da região.

\section{Palavras-Chave}

Fluxos em rede; distribuição; exportação. 


\section{Abstract}

Macedo, Maria Paula Boechat Borges de; Diallo, Madiagne (Advisor). Analysis of Potential Export Bases of Heineken Beer in South America. Rio de Janeiro, 2008. 50p. MSc. Dissertation - Departamento de Engenharia Industrial, Pontifícia Universidade Católica do Rio de Janeiro.

The Heineken Beer is present in eleven Latin-American countries. Some of them have their demand supplied by breweries located in their own countries, others by the importation from breweries located in other countries of the region and there are still those that depend on the beer exported from the headquarters of the company, in The Netherlands. Considering the Latin-American markets that have their demand regularly supplied by breweries located abroad, we identify three different origins: Holland, Argentina and Chile. Motivated by the large volume of beer imported from Heineken in The Netherlands, by the costs generated by such importations and also by the problems brought about by the difficulties found by some local breweries in order to meet their foreign demand by "local" I mean located in the region of Latin America -, this dissertation is developed. The aim of this study is to analyze the dynamics of the distribution network of Heineken Beer throughout Latin-America, in order to identify potential new export bases and propose a better organization of the export flow. The objective is to optimize such flow, reducing costs through the regionalization of the so-called sources, which are nothing other than breweries exporting to and supplying the Latin-American countries. In order to fulfill this purpose, potential sources will be tested and, by making use of logistics tools, the scenarios that meet the demand of the region in a more effective way will be evaluated.

\section{Keywords}

Network flows; distribution; exportation. 


\section{Sumário}

$\begin{array}{ll}\text { Introdução } & 10\end{array}$

Capítulo I: A Organização do Grupo Heineken 13

1.1 Estrutura Regional 13

1.2 Os Departamentos de Serviço ao Cliente e Logística CustomerService Offices (CSO's)

1.3 O CSO Latin America (CSO Latam) 17

Capítulo II: Mapeamento da Distribuição na América do Sul,

Panamá e México 19

2.1 Heineken na América Latina - Cenário Atual 19

2.2 Operação Triangular 21

2.3 Capacidade de Produção das Plantas Cervejeiras 23

2.4 Demanda dos Distribuidores (Importadores) 24

2.5 Os SKU's (Stock Keeping Units) 25

2.6 Volumes Atuais de Exportação 26

2.7 Os Custos de Importação 27

2.7.1 A Globalização do Comércio 27

2.7.2 O Mercosul 27

2.7.3 Acordos Comerciais Bilaterais 28

2.7.4 Custos Considerados 29

2.7.5 Cenário Atual 32

Capítulo III: Modelagem pelo Modelo de Transportes e Resolução 37

3.1 O Modelo de Transportes 37

3.2 Pressupostos para Cálculo 38

3.3 Modelagem 39

3.3.1 Manutenção da Política de Mono-sourcing 39

3.3.2 Resolução pelo Solver do Excel para o Modelo

Mono-sourcing 41

3.3.3 Admitindo-se Solução com Multi-sourcing 43

Capítulo IV: Conclusão e Considerações Finais 46 
Referências Bibliográficas

Apêndice 1: Detalhamento dos Custos Incorridos na Importação de Latas

Apêndice 2: Detalhamento dos Custos Incorridos na Importação de Garrafas 